Research

\title{
Changes in sedation management in German intensive care units between 2002 and 2006: a national follow-up survey
}

\author{
Jörg Martin ${ }^{1}$, Martin Franck², Stefan Sigel ${ }^{1}$, Manfred Weiss ${ }^{3}$ and Claudia Spies ${ }^{2}$
}

\author{
1'Department of Anesthesiology, Intensive Care Medicine and Pain Therapy, Hospital am Eichert, Eichertstraße 3, 73035 Göppingen, Germany \\ 2Department of Anesthesiology and Intensive Care Medicine, Charité-Universitätsmedizin Berlin, Campus Mitte, Charitéplatz 1, 10117 Berlin, \\ Germany \\ ${ }^{3}$ Department of Anesthesiology, Universitätsklinikum Ulm, Steinhövelstraße 9, 89075 Ulm, Germany
}

Corresponding author: Jörg Martin, Joerg.Martin@email.de

Received: 27 Sep 2007 Revisions requested: 5 Nov 2007 Revisions received: 18 Nov 2007 Accepted: 6 Dec 2007 Published: 6 Dec 2007

Critical Care 2007, 11:R124 (doi:10.1186/cc6189)

This article is online at: http://ccforum.com/content/11/6/R124

(c) 2007 Martin et al.; licensee BioMed Central Ltd.

This is an open access article distributed under the terms of the Creative Commons Attribution License (http://creativecommons.org/licenses/by/2.0), which permits unrestricted use, distribution, and reproduction in any medium, provided the original work is properly cited.

\begin{abstract}
Background The aim of this study, conducted in 2006, was to find out whether changes in sedation management in German intensive care units took place in comparison with our survey from 2002.

Methods We conducted a follow-up survey with a descriptive and comparative cross-sectional multi-center design. A postal survey was sent between January and May 2006, up to four times, to the same 269 hospitals that participated in our first survey in 2002. The same questionnaire as in 2002 was used with a few additional questions.
\end{abstract}

Results Two hundred fourteen (82\%) hospitals replied. Sixtyseven percent of the hospitals carried out changes in sedation management since the 2002 survey. Reasons for changes were published literature (46\%), national guidelines (29\%), and scientific lectures (32\%). Sedation protocols ( $8 \%$ versus $52 \%$ ) and a sedation scale ( $21 \%$ versus $46 \%$ ) were used significantly more frequently. During sedation periods of up to 24 hours, significantly less midazolam was used (46\% versus $35 \%)$. In comparison to 2002, sufentanil and epidural analgesia were used much more frequently in all phases of sedation, and fentanyl more rarely. For periods of greater than 72 hours, remifentanil was used more often. A daily sedation break was introduced by $34 \%$ of the hospitals, and a pain scale by $21 \%$.

Conclusion The increased implementation of protocols and scoring systems for the measurement of sedation depth and analgesia, a daily sedation break, and the use of more shortacting analgesics and sedatives account for more patientoriented analgesia and sedation in 2006 compared with 2002.

\section{Introduction}

Most mechanically ventilated patients require analgesia and sedation. Adequate analgesia and sedation should ensure that the patient can receive intensive medical care without undue stress or pain [1]. As with insufficient sedation, excessively deep sedation also may lead to increased morbidity, increased costs, and a prolonged stay in the intensive care unit (ICU) [24]. Recent advances with drugs that are more controllable, better ventilation techniques and sedation strategies, and the use of scoring systems and sedation protocols enable optimization of sedation $[1,5,6]$. However, the optimal sedation strategy remains a controversial issue at present. Despite controversies, a shift from deeper to lighter sedation, thereby maintaining the normal circadian rhythm, is emerging within the published literature $[1,5,7]$.

Apart from sedation, emphasis should be placed on adequate monitoring of analgesia. Whipple and colleagues [8] have shown that $70 \%$ of patients admitted to an ICU recollected suffering pain. Regular review of pain scores followed by appropriate therapy leads to a reduction in morbidity and a reduction in duration of mechanical ventilation [9].

Soliman and colleagues [10] have shown that sedation practice and the use of differing scoring systems and guidelines are quite different between countries. In 2002, a national survey of analgesia and sedation practice in German ICUs was

$\overline{\mathrm{ICU}}=$ intensive care unit; RASS $=$ Richmond agitation sedation scale; RSS = Ramsay sedation scale. 
undertaken [11]. The goal of the present study was to find out whether new trends or significant changes in ICU analgesia and sedation practice among mechanically ventilated patients in ICUs have emerged since the last survey [11] and the publication of national guidelines for analgesia and sedation practice in Germany in 2005 [12]. The major recommendations of the guidelines consist of the application of scores for analgesia and sedation, with a patient-oriented depth of sedation, implementation of written sedation protocols, application of short-acting drugs, and use of regional anesthesia techniques.

\section{Materials and methods}

This study is a descriptive, comparative, multi-center follow-up study to the survey performed in 2002 [11]. The same address database was used as in the first study. In total, 254 general hospitals and 15 university hospitals were contacted. All ICUs were run by an anesthesiological department and include surgical and interdisciplinary adult ICUs. The survey was submitted to the chairmen of the departments up to four times in the period January to May 2006. The response rate was $82 \%$ and most of the forms were filled out by the head of the ICU. The questionnaire corresponded to the first questionnaire, although a few questions were added.

\section{The questionnaire}

A modified version of the questionnaire used in 2002 [11] was used. Questions were added relating to the use of pain scores [9], daily sedation breaks [2,13], and the reasons for any changes in sedation practice. Since no department used a validated instrument to score for delirium in the previous survey, we did not ask about delirium in the present questionnaire.

\section{Part 1: General data}

General data included size and type of ICU, number of beds, case mix index, number of days in the ICU, average length of stay, number of mechanically ventilated patients per year, and average duration of ventilation.

Part 2: Data relating to analgesia and sedation These data included changes accomplished in sedation management since 2002 , use of scores for pain severity and seda- tion depth, daily sedation break, implementation of written protocols, reasons for choice of medications used, and use of muscle relaxants.

Part 3: Questions relating to changes in analgesia and sedation practice occurring since the last survey

These questions focused on reasons for any potential changes that had occurred in the interim period between this survey and the 2002 survey.

Part 4: Pharmacological and regional analgesia techniques for analgesia and sedation

As was the case with the first survey, the sedation periods were divided into the following groups according to the American [14] and German [12] guidelines: sedation up to 24 hours, 24 to 72 hours, greater than 72 hours, and analgesia and sedation during weaning from mechanical ventilation.

\section{Statistics}

Data were collected in a Microsoft Access 2002 database and analyzed with Microsoft Excel 2002 (Microsoft Corporation, Redmond, WA, USA) and SPSS for Windows (version 13.0; SPSS Inc., Chicago, IL, USA). Responses to part 2 of the questionnaire were given as 'yes' or 'no'. Responses to parts 3 and 4 may include more than one answer. Univariate statistical analyses were carried out depending on the scaling of the data, using either the Mann-Whitney $U$ test or the chisquare test. Analyses were assigned as exploratory. Therefore, no multiple adjustments were carried out. Statistical significance (in the sense of exploratory analyses) was set at a $p$ value of greater than 0.05 .

\section{Results}

The response rate was $82 \%$ (214 out of 261). More than $90 \%$ of the ICUs that responded in 2002 also participated in this survey. At this rate of response, non-responder bias is insignificant [15]. There was no significant difference to the 2002 survey response rate $(82 \%)$. All data were entered into the analyses. In regard to general data (Table 1), there were significant differences in the number of ICU beds in university hospitals and in general hospitals (9 versus 10) and also in the

Table

General data of the surveyed intensive care units in 2002 and 2006

\begin{tabular}{lccc}
\hline & 2002 Median (minimum, maximum) & 2006 Median (minimum, maximum) & $P$ value \\
\hline Intensive care beds (university hospitals) & $14(8,24)$ & $24(10,32)$ & 0.09 \\
Intensive care beds (general hospitals) & $9(2,27)$ & $10(4,40)$ & 0.02 \\
Patients per year (university hospitals) & $1,481(517,2,500)$ & $2,000(700,2,860)$ & $1,000(120,4,578)$ \\
Patients per year (general hospitals) & $930(120,5,297)$ & $5,000(3,000,13,900)$ & 0.03 \\
Nursing care days (university hospitals) & $4,950(2,000,7,900)$ & $3,000(250,15,462)$ & 0.5 \\
Nursing care days (general hospitals) & $2,704(400,7,830)$ & 0.06 \\
\hline
\end{tabular}

The Mann-Whitney $U$ test was used to calculate $p$ values. 
Table 2

\begin{tabular}{|c|c|c|c|}
\hline & $2002(n=220)$ & $2006(n=214)$ & $P$ value \\
\hline & \multicolumn{3}{|c|}{ Percentage $(95 \% \mathrm{Cl})$} \\
\hline Sedation score & $8(-4$ to 20$)$ & 51 (41 to 60$)$ & $<0.001$ \\
\hline Sedation protocol & 21 (9 to 32 ) & 46 (36 to 56$)$ & $<0.001$ \\
\hline Medication selection according to sedation duration & 92 (88 to 96$)$ & 93 (89 to 97$)$ & 0.5 \\
\hline Oral procedure instructions & 44 (33 to 53$)$ & 93 (89 to 97$)$ & $<0.001$ \\
\hline Day-night rhythm & 81 (75 to 87$)$ & $88(84$ to 94$)$ & $<0.001$ \\
\hline Consideration of costs affecting drug selection & 62 (54 to 70$)$ & 55 (46 to 64$)$ & 0.4 \\
\hline
\end{tabular}

The chi-square test was used to calculate $p$ values. $\mathrm{Cl}$, confidence interval; $\mathrm{n}$, number of positive answers.

number of patients treated annually $(9,330$ versus 1,000$)$.

\section{Process data}

Whereas only $8 \%$ of hospitals used a sedation scale in the first survey, this number rose to $51 \%$ in the present survey. We do not know how these scales were directed at the individual patient level in terms of comparing target and actual sedation levels. The Ramsay sedation scale (RSS) [16] was used almost exclusively, and only one hospital referred to use of the Richmond agitation sedation scale (RASS) [17]. Only numeric rating scales and visual analogue scales were used as a pain scale. Furthermore, sedation protocols were employed significantly more often (by $46 \%$ of respondents compared with $21 \%$ in the first survey). Oral procedure instructions (departmental consensus) were introduced in $93 \%$ of the surveyed hospitals, and this differed significantly from the first survey. Eighty-eight percent of the hospitals endeavored to maintain a day-night rhythm (Table 2).

\section{Changes in analgesia and sedation practice}

Sixty-seven percent (95\% confidence interval: 37\% to 97\%) of hospitals changed analgesia and sedation practice in the years 2002 to 2006 . Reasons given for these changes ranged from the publication of the S2e guidelines (29\%) to educational lectures (32\%). The most frequently quoted reason resulting in a change in analgesia and sedation policy was studying current literature (46\%). The reasons for the changes are summarized in Table 3. Pain scoring, although not surveyed in 2002, was found to be in use in $21 \%$ of cases. Thirty-four percent of respondents had introduced a daily sedation break (Table 4).

\section{Medications and techniques}

Only medications or interventions used by more than $5 \%$ of the respondents in any of the time periods were considered.

\section{Sedatives}

Propofol was used most frequently for sedation up to 24 hours (83\%). Midazolam was used significantly less frequently during this period than in the 2002 survey (46\% versus 35\%). In regard to periods of greater than 72 hours and weaning, use of sedatives did not change (Tables 5 and 6).

\section{Analgesics}

Fentanyl was applied less frequently in all phases of sedation compared with the first survey. In the present survey, sufentanil was used significantly more often in all stages. For all periods of longer than 24 hours, remifentanil was more commonly ordered, with the greatest increases in the phases of 24 to 72 hours (6\% versus $15 \%)$ and during weaning ( $2 \%$ versus $8 \%$ ). The rates of application of morphine, piritramide, or non-steroidal anti-inflammatory drugs were comparable (Tables 5 and 6).

\section{Adjuvant techniques for analgesia and sedation}

With regard to the use of clonidine, there was no difference compared with the 2002 survey. Ketamine (S) was significantly more commonly used in the interim, particularly in the case of long-term sedation greater than 72 hours (7\% versus $15 \%)$ and also during weaning (20\% versus $26 \%$ ). Patientcontrolled analgesia techniques are now significantly more widely applied during weaning than in 2002 (16\% versus $22 \%$ ). Similar to the earlier survey, neuromuscular blockade was not performed regularly during any of the sedation phases (Tables 5 and 6).

\section{Regional analgesia techniques}

Epidural analgesia was observed more frequently in all stages of sedation compared with the preliminary investigation. Peripheral nerve blocks were also performed significantly more often for stays of greater than 72 hours and during weaning. Patient-controlled epidural analgesia was applied more often during short-term sedation periods (less than 24 hours) in the 2006 survey than in that of 2002 (Tables 5 and 6).

\section{Discussion}

The goal of the present survey was to clarify whether a change has taken place in analgesia and sedation practice since the last survey in 2002 and after the publication of national practice guidelines on the subject [12]. Underlying the same questionnaire as in 2002, we are able to compare and contrast our 
Table 3

Reasons given for changes in sedation management since the last survey (2002)

\begin{tabular}{lc}
\hline Changes in sedation management & Percentage (95\% Cl) $n=214$ \\
\hline Resulting from S2e guidelines & $29(18$ to 40$)$ \\
Resulting from change in department leadership & $10(-3$ to 23$)$ \\
Following lectures & $32(21$ to 42$)$ \\
Following literature & $46(36$ to 56$)$ \\
Other & $13(-6$ to 32$)$ \\
\hline
\end{tabular}

$\mathrm{Cl}$, confidence interval; $\mathrm{n}$, number of positive answers.

findings. The most striking results are the significantly increased use of sedation scales and written sedation protocols.

The RSS [16] was the scale most frequently used in the present survey, with only one institution employing the RASS [17]. In recent reviews, Fraser and Rieker [18,19] demonstrated that only the consistent use of a validated sedation scale led to a reduction in the duration of mechanical ventilation, as well as reduced length of ICU stay. Written sedation guidelines were used significantly more often in the present survey. Employment of sedation guidelines enables reductions in both duration of mechanical ventilation and use of intensive care time [20], with consequent savings in medical costs [21]. However, as shown by Elliott and colleagues [22] and Andrews and colleagues [23], these positive changes are achieved only with sufficient training of the personnel involved and with adaptation of the guidelines to the local hospital environment. Meanwhile, a daily sedation break, as suggested by Kress and coworkers [2], is currently employed in one third of our surveyed hospitals. In addition, pain monitoring is increasingly performed. Chanques and colleagues [9] have pointed out that by monitoring and optimizing pain management, the number of nosocomial infections and the length of mechanical ventilation can be reduced. The use of analgesia and sedation scales, as well as the use of written guidelines, should result in avoidance of oversedation of patients, as described by Martin and colleagues [24].

As with the Danish follow-up questionnaire on sedation and analgesia in the ICU [25], a trend is being observed in Germany toward the application of analgesics and sedatives that are more controllable. For sedation periods of less than 72 hours, midazolam is used significantly less frequently than in 2002. Carson and colleagues [26] have shown the more favorable pharmacokinetics of propofol versus benzodiazepines. In terms of analgesics, the same development emerges. Fentanyl is used less frequently in all stages of sedation, but sufentanil is increasingly used. Remifentanil was applied more often for sedation periods of up to 24 hours, sedation for less than 72 hours, and during weaning. Breen and colleagues [27] and Muellejans and colleagues [28] have shown that using remifentanil in that way leads to a significantly shortened ventilation time compared with a control group. Ketamine (S) was more frequently used in the phases up to 24 hours and from 24 to 72 hours than in 2002. However, as has been shown by Ostermann and colleagues [29], there has been very little investigation of long-term use of ketamine sedation. Nevertheless, an important reason favoring the use of ketamine is the absence of a significant effect on bowel motility [30].

Epidural analgesia was performed more frequently in the phases of greater than 72 hours and during weaning than in

Table 4

Changes accomplished in sedation management since 2002

\begin{tabular}{lc}
\hline Changes & Percentage $(95 \% \mathrm{Cl}) n=214$ \\
\hline Sedatives changed & $33(22$ to 44$)$ \\
Analgesia changed & $31(20$ to 42$)$ \\
Regional techniques introduced & $19(7$ to 31$)$ \\
Pain scoring introduced & $21(9$ to 33$)$ \\
Daily sedation break & $34(23$ to 45$)$ \\
Sedation protocol implemented & $23(11$ to 35$)$ \\
Other & $4(-9$ to 17$)$ \\
\hline
\end{tabular}

$\mathrm{Cl}$, confidence interval; $\mathrm{n}$, number of positive answers. 
Table 5

\begin{tabular}{|c|c|c|c|c|c|c|}
\hline \multirow[b]{3}{*}{ Year } & \multicolumn{3}{|c|}{ Less than 24 hours } & \multicolumn{3}{|c|}{24 to 72 hours } \\
\hline & \multicolumn{2}{|c|}{ Percentage $(95 \% \mathrm{Cl})$} & \multirow[t]{2}{*}{$P$ value } & \multicolumn{2}{|c|}{ Percentage $(95 \% \mathrm{Cl})$} & \multirow[t]{2}{*}{$P$ value } \\
\hline & $2002 n=220$ & $2006 n=214$ & & $2002 n=220$ & $2006 n=214$ & \\
\hline Midazolam & 45.9 (36.1 to 55.6$)$ & 34.6 (23.7 to 45.4$)$ & $<0.001$ & 77.3 (71.0 to 83.6$)$ & 62.2 (53.9 to 70.4 ) & $<0.001$ \\
\hline Propofol & 81.4 (75.7 to 87.1$)$ & 82.7 (77.1 to 88.3 ) & 0.6 & $55,9(47.2$ to 64.7$)$ & 67.3 (59.6 to 74.9 ) & $<0.001$ \\
\hline Remifentanil & $5.9(-6.9$ to 18.7$)$ & 16.8 (4.6 to 29.0 ) & $<0.001$ & $2.3(-10.8$ to 15.3$)$ & $7.9(-4.9$ to 20.8$)$ & $<0.002$ \\
\hline Fentanyl & 40.0 (29.8 to 50.3$)$ & 27.1 (15.7 to 38.5$)$ & $<0.001$ & $55.9(47.1$ to 64.7$)$ & 40.7 (30.3 to 51.0 ) & $<0.001$ \\
\hline Sufentanil & 35.0 (24.4 to 45.7$)$ & 41.6 (31.4 to 51.8$)$ & $<0.05$ & 47.7 (38.2 to 57.3$)$ & 58.4 (49.8 to 67.1$)$ & $<0.002$ \\
\hline Piritramide & 38.2 (27.8 to 48.6$)$ & 35.1 (24.3 to 45.8 ) & 0.3 & 15.5 (3.3 to 27.6 ) & 16.8 (4.6 to 29.0$)$ & 0.6 \\
\hline Morphine & 8.6 (-4.0 to 21.3$)$ & 7.5 (-5.4 to 20.4$)$ & 0.5 & 4.5 (-8.4 to 17.5$)$ & $7.9(-4.9$ to 20.8$)$ & 0.06 \\
\hline PCA & 25.5 (14.0 to 36.9 ) & 28.5 (17.2 to 39.8$)$ & 0.3 & 15.5 (3.3 to 27.6 ) & 21.5 (9.6 to 33.4 ) & $<0.001$ \\
\hline Ketamine (S) & $6.8(-5.9$ to 19.6$)$ & 14.5 (2.1 to 26.9 ) & 0.001 & 20.0 (8.2 to 31.8$)$ & 25.7 (14.2 to 37.2$)$ & $<0.001$ \\
\hline Clonidine & 35.9 (25.3 to 46.5$)$ & 33.6 (22.7 to 44.6$)$ & 0.5 & 48.2 (38.7 to 57.7$)$ & 49.5 (40.0 to 59.1$)$ & 0.7 \\
\hline NSAIDs & 26.8 (15.6 to 38.2 ) & 23.8 (12.1 to 35.5$)$ & 0.3 & 13.2 (0.8 to 25.5$)$ & 16.8 (4.6 to 29.0 ) & 0.1 \\
\hline NMBAs & $3.6(-9.3$ to 16.6$)$ & 0.0 & 0.5 & 0.0 & 0.0 & n.c. \\
\hline PNB & 15.5 (3.3 to 27.6 ) & 23.8 (12.1 to 35.5$)$ & 0.004 & $12.7(0.4$ to 25.1$)$ & 22.0 (10.1 to 33.8$)$ & $<0.001$ \\
\hline PCEA & 7.3 (-5.5 to 20.0$)$ & 11.7 (-0.9 to 24.3$)$ & 0.04 & $5.9(-6.9$ to 18.7$)$ & $9.8(-2.9$ to 22.5$)$ & 0.05 \\
\hline Epidural & 68.2 (60.8 to 75.7$)$ & 72.0 (64.9 to 79.1$)$ & 0.5 & 59.1 (50.7 to 67.6$)$ & $73.8(67.0$ to 80.7$)$ & $<0.001$ \\
\hline
\end{tabular}

The chi-square test was used to calculate $p$ values. $\mathrm{Cl}$, confidence interval; $\mathrm{n}$, number of positive answers; n.c., not calculated; NMBAs, neuromuscular blocking agents; NSAIDs, non-steroidal anti-inflammatory drugs; PCA, patient-controlled analgesia; PCEA, patient-controlled epidural analgesia; PNB, peripheral nerve block.

the survey of 2002. As has been shown by Brodner and colleagues [31] and in the meta-analysis by Rodgers and colleagues [32], the perioperative use of epidural analgesia leads to both shortening of intensive care stay as well as lowering the incidence of cardiac and pulmonary complications. Thus, this approach of epidural analgesia is recommended in the German guidelines on analgesia and sedation in the ICU [12].

In total, two thirds (67\%) of those taking part in the present survey reported changes in analgesia and sedation management since the last inquiry. Changes were induced by recent literature, scientific lectures, publication of national guidelines in 2005 [12], and a change in departmental leadership. Nevertheless, this current survey merely demonstrates that knowledge regarding analgesia and sedation policy has changed. Whether a real change in practice has occurred at the patient's bedside cannot be stated with certainty. In the implementation of guidelines in health care, large barriers to change exist [33], and so all parties of interest must be involved and motivated in order to effect changes in the daily treatment routine [34]. To evaluate actual analgesia and sedation practice, patient-centered investigations similar to those of Martin and colleagues [24] and Payen and colleagues [35] are needed.

\section{Conclusion}

These results show that changes in analgesia and sedation practice among intensive care patients have taken place by the time of this survey, which was conducted 4 years after the initial investigation and 1 year after the appearance of national guidelines. In summary, the increased use of scoring systems for pain severity and sedation depth, a daily sedation break, the implementation of protocols, and the use of more shortacting medications for analgesia and sedation conform to the guidelines on patient-oriented analgesia and sedation. Although we see some areas of improvement, further efforts are necessary to reach widespread implementation of the analgesia and sedation guidelines into practice. Further patient-centered studies are needed to determine the extent to which these changes translate into performance at the patient's bedside. As wide variations in sedation practice exist internationally [10], further national investigations are needed to improve national sedation and analgesia policies, and, in the long run, to yield international consensus.

\section{Competing interests}

JM has been employed by GlaxoSmithKline (Uxbridge, Middlesex, UK) and B. Braun Melsungen AG (Melsungen, Germany) to present educational talks on therapy for analgesia and seda- 
Table 6

Comparison of the techniques and agents used for analgesia and sedation in 2002 and 2006

\begin{tabular}{|c|c|c|c|c|c|c|}
\hline \multirow[b]{3}{*}{ Year } & \multicolumn{3}{|c|}{ More than 72 hours } & \multicolumn{3}{|c|}{ Weaning } \\
\hline & \multicolumn{2}{|c|}{ Percentage $(95 \% \mathrm{Cl})$} & \multirow[t]{2}{*}{$P$ value } & \multicolumn{2}{|c|}{ Percentage $(95 \% \mathrm{Cl})$} & \multirow[t]{2}{*}{$P$ value } \\
\hline & $2002 n=220$ & $2006 n=214$ & & $2002 n=220$ & $2006 n=214$ & \\
\hline Midazolam & 90.5 (86.4 to 94.5$)$ & 92.1 (88.3 to 95.8$)$ & 0.4 & 34.1 (23.4 to 44.8$)$ & 32.2 (21.2 to 43.3$)$ & 0.06 \\
\hline Propofol & 26.4 (15.0 to 37.7$)$ & $22.9(11.1$ to 34.7$)$ & 0.2 & 72.3 (65.3 to 79.3 ) & 75.2 (68.6 to 81.9$)$ & 0.3 \\
\hline Remifentanil & $1.4(-11.8$ to 14.5$)$ & $3.7(-9.4$ to 16.9$)$ & 0.06 & $5.9(-6.9$ to 18.7$)$ & 15.0 (2.6 to 27.3 ) & $<0.001$ \\
\hline Fentanyl & $65.0(57.2$ to 72.8$)$ & 53.7 (44.6 to 62.9$)$ & $<0.001$ & $30.0(19.0$ to 41.0$)$ & 21.5 (9.6 to 33.4 ) & 0.002 \\
\hline Sufentanil & 43.6 (33.7 to 3.5 ) & 51.4 (42.1 to 0.7$)$ & 0.02 & 41.8 (31.8 to 51.9$)$ & 49.5 (40.0 to 9.1$)$ & 0.02 \\
\hline Piritramide & 9.1 (-3.5 to 21.7$)$ & 7.9 (-4.9 to 20.8$)$ & 0.5 & 25.5 (14.1 to 36.9$)$ & 24.3 (12.6 to 36.0$)$ & 0.7 \\
\hline Morphine & $7.3(-5.5$ to 20.0$)$ & $9.8(-2.9$ to 22.5$)$ & 0.2 & 8.6 (-4.0 to 21.3$)$ & $9.4(-3.4$ to 22.1$)$ & 0.7 \\
\hline PCA & 9.5 (-3.0 to 22.1$)$ & $7.0(-5.9$ to 19.9$)$ & 0.5 & $(-0.1$ to 24.7$)$ & $12.2(-0.4$ to 24.7$)$ & 0.9 \\
\hline Ketamine (S) & 19.1 (13.6 to 36.4$)$ & 19.6 (7.6 to 31.6$)$ & 0.7 & $5.0(-7.9$ to 17.9$)$ & 4.2 (-8.9 to 17.3$)$ & 0.7 \\
\hline Clonidine & $56.4(47.7$ to 65.1$)$ & 52.8 (43.6 to 62.0$)$ & 0.3 & 62.7 (54.6 to 70.8$)$ & 58.9 (50.3 to 67.5$)$ & 0.5 \\
\hline NSAIDs & $10.5(-2.1$ to 23.0$)$ & $10.3(-2.4$ to 22.9$)$ & 0.9 & 14.1 (1.8 to 26.3 ) & 19.2 (7.1 to 31.2$)$ & 0.06 \\
\hline NMBAs & 0.0 & n.c. & n.c. & 0.0 & n.c. & n.c. \\
\hline PNB & $10.0(-2.5$ to 22.5$)$ & 14.5 (2.1 to 26.9 ) & 0.6 & 7.7 (-5.0 to 20.4$)$ & 13.6 (1.1 to 26.0$)$ & 0.01 \\
\hline PCEA & $4.1(-8.9$ to 17.0$)$ & $3.7(-9.4$ to 16.9$)$ & 0.8 & 4.6 (-8.4 to 17.5$)$ & $5.6(-7.4$ to 18.6$)$ & 0.5 \\
\hline Epidural & 45.9 (36.2 to 5.6$)$ & $56.5(47.7$ to 5.4$)$ & $<0.005$ & 42.3 (32.2 to 52.3 ) & 52.8 (43.6 to 62.0$)$ & $<0.005$ \\
\hline
\end{tabular}

The chi-square test was used to calculate $p$ values. $\mathrm{Cl}$, confidence interval; $\mathrm{n}$, number of positive answers; n.c., not calculated; NMBAs, neuromuscular blocking agents; NSAIDs, non-steroidal anti-inflammatory drugs; PCA, patient-controlled analgesia; PCEA, patient-controlled epidural analgesia; PNB, peripheral nerve block.

\section{Key messages \\ - According to our 2006 follow-up survey of German intensive care units, the following changes have occurred since 2002: \\ - Increased use of scoring systems for pain severity and sedation depth. \\ - Use of more short-acting medications for analgesia and sedation. \\ - A trend toward conformity with the national guidelines on patient-oriented analgesia and sedation. \\ - Also according to our follow-up survey, a daily sedation break is currently employed in only $34 \%$ of the hospitals.}

tion and economics. The other authors declare that they have no competing or financial interests.

\section{Authors' contributions}

JM made substantial contributions to the conception, design, analysis and interpretation of data. MF was involved in drafting the article and revising it critically for important intellectual content. SS performed the acquisition, analysis and interpretation of data. MW participated in the design and coordination and helped to draft the manuscript. CS made substantial contributions to the conception, design, analysis and interpretation of data.

All authors read and approved the final manuscript.

\section{References}

1. Kress JP, Hall JB: Sedation in the mechanically ventilated patient. Crit Care Med 2006, 34:2541-2546.

2. Kress JP, Pohlman AS, O'Connor MF, Hall JB: Daily interruption of sedative infusions in critically ill patients undergoing mechanical ventilation. $N$ Engl J Med 2000, 342:1471-1477.

3. Freire AX, Afessa B, Cawley P, Phelps S, Bridges L: Characteristics associated with analgesia ordering in the intensive care unit and relationships with outcome. Crit Care Med 2002, 30:2468-2472.

4. Riker RR, Fraser GL: Adverse events associated with sedatives, analgesics, and other drugs that provide patient comfort in the intensive care unit. Pharmacotherapy 2005, 25:8S-18S.

5. Brattebo G, Hofoss D, Flaatten H, Muri AK, Gjerde S, Plsek PE: Effect of a scoring system and protocol for sedation on duration of patients' need for ventilator support in a surgical intensive care unit. BMJ 2002, 324:1386-1389.

6. Kollef MH, Levy NT, Ahrens TS, Schaiff R, Prentice D, Sherman G: The use of continuous i.v. sedation is associated with prolongation of mechanical ventilation. Chest 1998, 114:541-548.

7. Pochard F, Lanore JJ, Bellivier F, Ferrand I, Mira JP, Belghith M, Brunet $F$, Dhainaut JF: Subjective psychological status of severely ill patients discharged from mechanical ventilation. Clin Intensive Care 1995, 6:57-61. 
8. Whipple JK, Lewis KS, Quebbeman EJ, Wolff M, Gottlieb MS, Medicus-Bringa M, Hartnett KR, Graf M, Ausman RK: Analysis of pain management in critically ill patients. Pharmacotherapy 1995, 15:592-599.

9. Chanques G, Jaber S, Barbotte E, Violet S, Sebbane M, Perrigault PF, Mann C, Lefrant JY, Eledjam JJ: Impact of systematic evaluation of pain and agitation in an intensive care unit. Crit Care Med 2006, 34:1691-1699.

10. Soliman HM, Melot C, Vincent JL: Sedative and analgesic practice in the intensive care unit: the results of a European survey. $\mathrm{Br} J$ Anaesth 2001, 87:186-192.

11. Martin J, Parsch A, Franck M, Wernecke KD, Fischer M, Spies C: Practice of sedation and analgesia in German intensive care units: results of a national survey. Crit Care 2005, 9:R117-R123.

12. Martin J, Basell K, Burkle H, Hommel J, Huth G, Kessler P, Kretz F, Putensen C, Quintel M, Tonner P, Tryba M, Scholz J, Schüttler J, Wappler F, Spies C: Analgesie und Sedierung in der Intensivmedizin - Kurzversion, S2-Leitlinien der Deutschen Gesellschaft für Anästhesiologie und Intensivmedizin. Analgesia and sedation in intensive care medicine - short version, S2-guidelines of the German society of anaesthesiology and intensive care medicine. Anästh Intensivmed 2005, 46:1-20.

13. Schweickert WD, Gehlbach BK, Pohlman AS, Hall JB, Kress JP: Daily interruption of sedative infusions and complications of critical illness in mechanically ventilated patients. Crit Care Med 2004, 32:1272-1276.

14. Jacobi J, Fraser GL, Coursin DB, Riker RR, Fontaine D, Wittbrodt ET, Chalfin DB, Masica MF, Bjerke HS, Coplin WM, Crippen DW, Fuchs BD, Kelleher RM, Marik PE, Nasraway SA Jr, Murray MJ, Peruzzi WT, Lumb PD, Task Force of the American College of Critical Care Medicine (ACCM) of the Society of Critical Care Medicine (SCCM), American Society of Health-System Pharmacists (ASHP), American College of Chest Physicians: Clinical practice guidelines for the sustained use of sedatives and analgesics in the critically ill adult. Crit Care Med 2002, 30:119-141.

15. National Center for Education Statistics: Standard 2-2: NCES Statistical Standards. [http://nces.ed.gov/statprog/2002/ std2 2.asp].

16. Ramsay MA, Savege TM, Simpson BR, Goodwin R: Controlled sedation with alphaxalone-alphadolone. $\mathrm{Br}$ Med J 1974, 2:656-659.

17. Ely EW, Truman B, Shintani A, Thomason JW, Wheeler AP, Gordon S, Francis J, Speroff T, Gautam S, Margolin R, Sessler CN, Dittus RS, Bernard GR: Monitoring sedation status over time in ICU patients: reliability and validity of the Richmond AgitationSedation Scale (RASS). JAMA 2003, 289:2983-2991.

18. Fraser GL, Riker RR: Comfort without coma: changing sedation practices. Crit Care Med 2007, 35:635-637.

19. Fraser GL, Riker RR: Sedation and analgesia in the critically ill adult. Curr Opin Anaesthesiol 2007, 20:119-123.

20. Mascia MF, Koch M, Medicis JJ: Pharmacoeconomic impact of rational use guidelines on the provision of analgesia, sedation, and neuromuscular blockade in critical care. Crit Care Med 2000, 28:2300-2306.

21. Adam C, Rosser D, Manji M: Impact of introducing a sedation management guideline in intensive care. Anaesthesia 2006, 61:260-263.

22. Elliott R, McKinley S, Aitken LM, Hendrikz J: The effect of an algorithm-based sedation guideline on the duration of mechanical ventilation in an Australian intensive care unit. Intensive Care Med 2006, 32:1506-1514.

23. Andrews $\mathrm{P}$, Azoulay E, Antonelli M, Brochard L, Brun-Buisson C, De Backer D, Dobb G, Fagon JY, Gerlach H, Groeneveld J, Macrae D, Mancebo J, Metnitz P, Nava S, Pugin J, Pinsky M, Radermacher P, Richard C: Year in review in Intensive Care Medicine, 2006. l. Experimental studies. Clinical studies: brain injury, renal failure and endocrinology. Intensive Care Med 2007, 33:49-57.

24. Martin J, Franck M, Fischer M, Spies C: Sedation and analgesia in German intensive care units: how is it done in reality? Results of a patient-based survey of analgesia and sedation. Intensive Care Med 2006, 32:1137-1142.

25. Egerod I, Christensen BV, Johansen L: Trends in sedation practices in Danish intensive care units in 2003: a national survey. Intensive Care Med 2006, 32:60-66.

26. Carson SS, Kress JP, Rodgers JE, Vinayak A, Campbell-Bright $S$, Levitt J, Bourdet S, Ivanova A, Henderson AG, Pohlman A, Chang
L, Rich PB, Hall J: A randomized trial of intermittent lorazepam versus propofol with daily interruption in mechanically ventilated patients. Crit Care Med 2006, 34:1326-1332.

27. Breen D, Karabinis A, Malbrain M, Morais R, Albrecht S, Jarnvig IL, Parkinson $P$, Kirkham AJ: Decreased duration of mechanical ventilation when comparing analgesia-based sedation using remifentanil with standard hypnotic-based sedation for up to 10 days in intensive care unit patients: a randomised trial [ISRCTN47583497]. Crit Care 2005, 9:R200-R210.

28. Muellejans B, Matthey T, Scholpp J, Schill M: Sedation in the intensive care unit with remifentanil/propofol versus midazolam/fentanyl: a randomised, open-label, pharmacoeconomic trial. Crit Care 2006, 10:R91.

29. Ostermann ME, Keenan SP, Seiferling RA, Sibbald WJ: Sedation in the intensive care unit: a systematic review. JAMA 2000 283:1451-1459.

30. Zielmann S, Grote R: [The effects of long-term sedation on intestinal function]. Anaesthesist 1995, 44(Suppl 3):S549-S558

31. Brodner G, Van Aken H, Hertle L, Fobker M, Von Eckardstein A, Goeters $\mathrm{C}$, Buerkle $\mathrm{H}$, Harks A, Kehlet $\mathrm{H}$ : Multimodal perioperative management - combining thoracic epidural analgesia forced mobilization, and oral nutrition - reduces hormonal and metabolic stress and improves convalescence after major urologic surgery. Anesth Analg 2001, 92:1594-1600.

32. Rodgers A, Walker N, Schug S, McKee A, Kehlet H, van Zundert A, Sage D, Futter M, Saville G, Clark T, MacMahon S: Reduction of postoperative mortality and morbidity with epidural or spinal anaesthesia: results from overview of randomised trials. BMJ 2000, 321:1493.

33. Cabana MD, Rand CS, Powe NR, Wu AW, Wilson MH, Abboud PA, Rubin HR: Why don't physicians follow clinical practice guidelines? A framework for improvement. JAMA 1999, 282:1458-1465.

34. Bosse G, Breuer JP, Spies C: The resistance to changing guidelines - what are the challenges and how to meet them. Best Pract Res Clin Anaesthesiol 2006, 20:379-395.

35. Payen JF, Chanques G, Mantz J, Hercule C, Auriant I, Leguillou JL, Binhas M, Genty C, Rolland C, Bosson JL: Current practices in sedation and analgesia for mechanically ventilated critically il patients: a prospective multicenter patient-based study. Anesthesiology 2007, 106:687-695. 